\title{
Interpersonal Trust and Its Role in Organizations
}

\author{
Masoodul Hassan ${ }^{1}$, Nilüfer Vatansever Toylan ${ }^{2}$, Fatih Semerciöz ${ }^{3} \&$ Ibrahim Aksel $^{4}$ \\ ${ }^{1}$ Department of Commerce, Bahauddin Zakariya University, Multan, Pakistan \\ ${ }^{2}$ Kırklareli University, Kırklareli, Turkey \\ ${ }^{3}$ Faculty of Business Administration, Department of Management, Istanbul University, Avcllar Campus, Istanbul, \\ Turkey \\ ${ }^{4}$ Faculty of Economics and Administrative Sciences, Department of Business Management and Organization, \\ Pamukkale University, Kinikli Kampusu, Denizli, Turkey \\ Correspondence: Masoodul Hassan, Department of Commerce, Bahauddin Zakariya University, Multan, \\ Pakistan. E-mail: masoodulhassan99@gmail.com
}

Received: April 4, 2012 Accepted: May 15, $2012 \quad$ Online Published: July 1, 2012

doi:10.5539/ibr.v5n8p33～URL: http://dx.doi.org/10.5539/ibr.v5n8p33

An earlier version of this paper was presented at the International Scientific Conference held on 21 - 22 November, 2008 at Gabrovo.

\begin{abstract}
In the social sciences literature, the concept of "trust" as an important phenomenon has been increasingly recognized. Basically it shows us the nature and importance of establishing and maintenance of trust in building business to business and interpersonal relations. In particular, employees' trust in their leaders has been regarded as an effective tool behind positive organizational outcomes. Therfore, within the organizational context, the main purpose of this conceptual paper is to review the current literature on interpersonal trust, its antecedents and consequences. The review of the existing research has summarized the main findings on associations between participation in decision making, feedback from and to employees, employee empowerment, and interpersonal trust (between supervisor and employees). Finally, this conceptual paper has suggested that trust-building practices between managers and workers can positively lead to high productivity and organizational commitment in all the organizations whether public or private.
\end{abstract}

Keywords: organizational trust, participation, feedback, empowerment, productivity, organizational commitment

\section{Introducation}

Due to societal, economic, political, technological and global changes, organizations are becoming more responsive to changes and consequently discussion on organizational motivation, innovative leadership, and organizational trust have been regarded as an effective tools behind positive organizational outcomes. Importantly trust as an important phenomenon has been recognized across a number of social sciences and has primarily been concerned with issues related to trust within organizations (Blois, 1998). Moreover, keeping in view today's highly complex and diverse environments of organizations; Atkinson and Butcher (2003) provided that economic efficiency and hierarchy are not being accepted as contemporary management principles instead, co-operative relationships in the perspective of politically-driven structures, flexible networks, strategic alliances and entrepreneurial adaptability are being followed. Atkinson and Butcher (2003) further provided that early theorists have acknowledged the relevance of co-operation to organization but it has attained a new importance in present situation focusing more on relationships and less on authority and consequently, trust as a phenomenon becomes an important component of organizational social capital.

As this paper emphasizes the antecedents and consequences of interpersonal trust, so it is consistent with the extension of McGregor's (1960) Theory Y by Ouchi (1981) with Theory Z management theory (Nyhan, 2000). According to Costigan et al. (2007), Theory Y manager believes that employees can be fully trusted, broadening the decision-making authority of those employees whenever possible. Moreover, Costigan et al. (2007) suggested that McGregor's theory, which was originally developed for US managers, may be more applicable for the 
collectivist nations (i.e. Turkey, Russia Poland, and Pakistan).

In this article, it is proposed that Nyhan (2000) trust-based model, which was originally developed for public organizations, is equally applicable for all organizations whether public or private. Nyhan (2000) trust-based model proposed that participation in decision making, feedback from and to employees, and empowerment of employees lead to increased interpersonal trust (between supervisor and employee) in public organizations. This model furhter proposed that that these trust-building practices between supervisors and workers can lead to increased productivity and strengthened organizational commitment in public organizations. The main objective of this paper is to examine with the help of literature analysis that Nyhan's (2000) trust-based model is equally applicable for all organizations wheher public or private. Keeping in view this objective, this conceptual paper with the help literature review will start with the meaning of trust as applied within organizational context. A number of "key issues" which emerge as antecedents and consequences of interpersonal trust in shape of participation, feedback, empowerment and resulting organizational productivity and organizational commitment from the literature are then discussed.

\section{Literature Review}

\subsection{Trust}

Trust is conceptualized as an evolving affect, that is, an interacting set of emotions and assessments that develop and change over time (Young, 2006). According to Nootboom (2003), trust involves the trustor trusts a trustee in one or more aspects of behavior, under certain circumstances. Noteboom (2003) further provided that trustees can be individual people, but also collectives, such as organizations, and institutions. Robbins and Coulter (2005) have defined trust as the belief in the integrity, character, and ability of a leader. Mishra (1996) put trust as, "one party's willingness to be vulnerable to another party based on the belief that the latter party is competent, open, concerned and reliable”. According to Connell and Ferres (2003), trust does not come with a pay-check, it has to be earned - it is an ongoing process. Gordon and Scott (2006) provided the economics, psychological, and sociological point of views of trust: 1) Economists put trust as calculative or rational choice between the risks and benefits of trusting. In other words, a course of action is followed that will offer an individual with greatest benefit. 2) Psychologists conceptualize trust in terms of the traits of trustors and trustees and focuses upon a host of internal cognitions that personal traits yield. 3) On the other hand, sociologists see trust as socially embedded properties of relationships among people. Dietz (2006) provided that the concept of trust can be classified as a belief, as a decision, and as an action. Dietz (2006) further provided that to operate the concept of trust, it should go through the phases of belief, decision and an action. Gillespie and Mann (2004) provided that the fundamental importance of interpersonal trust for sustaining team and organizational effectiveness is increasingly being recognized. To explain this, Gillespie and Mann (2004) further provided that employees' trust in their superiors has been associated to a range of productivity-related processes and outcomes that include quality of communication and problem-solving, discretionary effort, organizational citizenship behavior, organizational commitment and the degree of employee turnover. Zhang, Tsui, Song, Li, and Jia (2008) argued that immediate supervisors have close contact with subordinates, consequently, their actions and behaviors are vital in determining the subordinates' attitudes; offer the foundation for trust. Stinglhamber and Vandenberghe (2003) found that supervisory support is a strong indicator of the quality of exchange relationships between employees and supervisors.

As this conceptual paper examines the nature and importance of interpersonal trust, it is necessary to analyze the antecedents and consequences of interpersonal trust. For this purpose, this conceptual paper has reviewed various articles and books. The findings of the same are presented as follows:

\subsection{Antecedents of Interpersonal Trust}

Interpersonal trust is among other factors for keeping social order within an organization. McAllister (1995) defines interpersonal trust as "the extent to which a person is confident in and willing to act on the basis of the words, actions, and decisions of another". One kind of interpersonal trust in organizations is hierarchical trust, which focuses on the supervisor-subordinate relationship. Much of the past-hierarchical trust research has examined the subordinate employee's trust of their immediate supervisor. Perry (2004) provided that credibility, decision participation, empowerment, and feedback were significant predictors of supervisor trust. Thoms, Dose, and Scott (2002) found significant relationship between job satisfaction and trust in the immediate supervisor and in management. What are the antecedents of Interpersonal Trust? First of all this conceptual study will look at the participation as an antecedent of interpersonal trust.

\subsubsection{Participation}

Where employees own the organization, its corporate philosophy and vision, participate in corporate planning 
and decision making, in that organization, sense of participation among the employees is at its peak. Wech (2002) provided that today conditions of being a competitor are to make arrangements for employees participate into the management and to create a trustful environment for their actively engagement into the management. According to Bijlsma and Koopman (2003), trust in leaders was found to be significantly related to participative decision making and meeting expectations of followers. Ladd, Travaglione, and Marshall (2006) found that participation in decision making appears to promote job satisfaction and commitment, whereas task variety and work effort foster participation. Wang (2003) provided that employee participation in decision making has been widely advocated as a means of increasing organizational effectiveness. Wang (2003) further provided that on one hand, employee participation in decision making played a critical role behind high productivity, ability, and the advancement of employee motivation and commitment. On the other hand, it permits management to gain benefit from employees' knowledge, expertise, and experience. Regarding trust-participative decision making relationship, Wang (2003) provided that trust in subordinates is regarded to be closely related to managerial willingness to utilize participative decision-making processes. Wang (2003) further asserted that it is important to understand how managers' trust influence their willingness to encourage employee participation under certain circumstances.

Now, this study will look at the second variable of the antecedents of interpersonal trust e.g., feedback.

\subsubsection{Feedback}

Robbins and Coulter (2005) have defined feedback as "the degree to which carrying out work activities required by a job results in the individual's obtaining direct and clear information about his or her performance". Coates (1996) argued that to create trust, you need to establish procedures to protect participants and let everyone know what they are. Knippen (1996) has mentioned the benefits of feedback such as meeting the boss's expectations better; better performance; an employee will have to come to boss less frequently with problems, questions or decisions; or having a more satisfied employee. Steelman and Rutkowski (2004) found that employees are more inclined to develop their job performance based on unfavorable feedback when the feedback source is considered to be credible, the feedback is of high quality and the feedback is given in a thoughtful manner. DeNisi and Kluger (2000) provided that performance feedback is an important factor behind high job satisfaction and motivation. DeNisi and Kluger (2000) further asserted that numerous decision-making and career development models contain a feedback loop highlighting that individuals learn on the basis of receiving feedback on their performance. Without monitoring, proper feedback cannot be provided and there is interaction between trust and monitoring to procure cooperation in interpersonal and inter-organization relations. To facilitate this discussion, Ferrin, Bligh, and Kohles (2007) provided that parties may rely on trust, monitoring, or some combination of the two to procure cooperation. Ferin et al. (2007) further suggested that trust and monitoring jointly and independently contribute to cooperation.

Third component under the discussion of antecedents of organizational trust is empowerment and research findings on this important variable are provided as under:

\subsubsection{Empowerment}

If the employees are provided opportunities for autonomy, choice, responsibility, and participation in decision making in organizations, they are said to be empowered by their superiors. Empowerment involves increasing the decision-making discretion of workers (Robbins \& Coulter, 2005). Chiang and Jang (2008) put empowering employees equal to understanding the needs and capabilities of employees, trusting them, and helping them to maximize their fulfillment while pursuing organizational goals. According to Chiang and Jang (2008), possible components of empowerment may involve individual employee perceptions, job structure and work environment, organizational structure and culture, managerial commitment and leadership, and training and reward systems. Bartram and Casimir (2007) found that empowerment played an important role in influencing organizational commitment and job satisfaction. Bartram and Casimir (2007) further found that as an important factor of empowerment, supervisory support has significant positive impact on job satisfaction. Tzafrir's (2004) study found a significant and positive influence of empowerment as one of the determinants of employees' trust in their managers. Klidas, Antonis, Berg and Wilderom's (2007) study that was conducted within the context of 16 luxury hotels in seven European countries found that customer-oriented culture and empowering management style are significantly correlated with behavior of empowered employees during the delivery of service to customers. Henkin and Moye (2006) in their study found that employees who feel empowered in their work environment tend to have higher levels of trust in their managers.

Now, this study will look at the consequences of interpersonal trust. 


\subsection{Consequences of Trust}

Research findings of Ladd et al. (2006) found that employees' participation in decision making increases autonomy, job satisfaction and affective commitment. Ladd et al. (2006) further concluded that affectively committed employees demonstrate more job satisfaction, work effort and pay more attention to their rewards. In this part of the study, productivity and organizational commitment, which are the consequences of trust, will be examined.

\subsubsection{Productivity}

Organizational productivity is the overall output of goods or services produced divided by the inputs needed to generate that output and resultant effectiveness can be measured through knowing that how appropriate organizational goals are and how well an organization is achieving those goals (Robbins \& Coulter, 2005). Trust is one of the key words for organizational productivity. It rests of how trustworthiness is your organization in the past years; people believe in your promise trustworthy (Augistine, 1995). Chiang and Jang (2008) found that supportive leadership behavior has a significant impact on managerial trust and organizational culture that as a result encourage psychological empowerment in Taiwan's hotel companies. An empirical study of Luo (2002) suggests that trust plays a stronger role in improving international strategic alliances performance such as sales and profitability. In Liu, Magjuka, and Lee's (2008) study, the results suggest that team structure is strongly associated with team performance, whereas trust and a collaboration conflict management style contribute to teamwork satisfaction. In Thoms, Dose, and Scott's (2002) study, it has found that accountability to both coworkers and management was positively related to trust in supervisors and managers. In an empirical study of Erdem and Zen (2003), the results show that teams with high levels of trust perform better and recommends that trust should be a primary value of the organizational culture. Costigan et al. (2007) report that increased trust is crucial to the firm's success, providing the necessary coordination of its human resources to implement its business strategy.

Now this paper is going to discuss the research findings on organizational commitment, which is the last variable as consequences of organizational trust in this study.

\subsubsection{Organizational Commitment}

Robbins and Coulter (2005) put organizational commitment as the degree to which an employee identifies with a particular organization and its goals and wishes to maintain membership in the organization. Brewer (1996) defined organizational commitment as the relative strength of an individual's identification with and involvement in a particular organization. Bambacas (2008) found that committed employees are believed to be more productive and less likely to quit, more dependable, perform better, produce more and are more involved. Pratt (1998) provided that organizational commitment is often associated with, how happy or satisfied am I with my organization. Stinglhamberi and Vandenberghe (2003) found that affective commitment to the supervisor was found to completely mediate the effect of perceived supervisor support on turnover. In Costa's (2003) study, work team trust appeared strongly related with team member's attitudes towards the organization. Tan and Tan (2000), in their study show that organizational trust is in positive relationship with organizational commitment and in negative relationship with the intention of leaving organization. In Gilder's (2003) study, it is concluded that contingent workers showed lower commitment to the team and to the organization, and displayed less favorable work-related behaviors than core employees.

\section{Conclusion}

In this study, with the help of literature review it is concluded that participation in decision making, feedback from and to employees and empowerment of employees lead to high level of trust. This study further concludes that trust-building practices between managers and workers can lead to high productivity and organizational commitment. After literature review done for this purpose, it is clear that Nyhan (2000) trust-based model is a practical model for both public and private organizations. In the light of information obtained from literature review it can be said that by encouraging participation of employees, providing positive feedback and with a true empowerment, it is possible to enhance organizational productivity and commitment in all types of organizations whether public or private. Therefore, consistent with Nyhan (2000), distinction between the factors that contribute to trust and the outcomes of trust, this conceptual paper sheds light on factors that are crucial for creating a trusting atmosphere. In the light of findings obtained from literature review, the trust-based model of Nyhan (figure 1) is proposed equally for both public and private organizations. In this conceptual model, major antecedents of interpersonal trust in shape of participation, feedback and empowerment and consequences of interpersonal trust in shape of productivity and organizational commitment have been shown accordingly. 


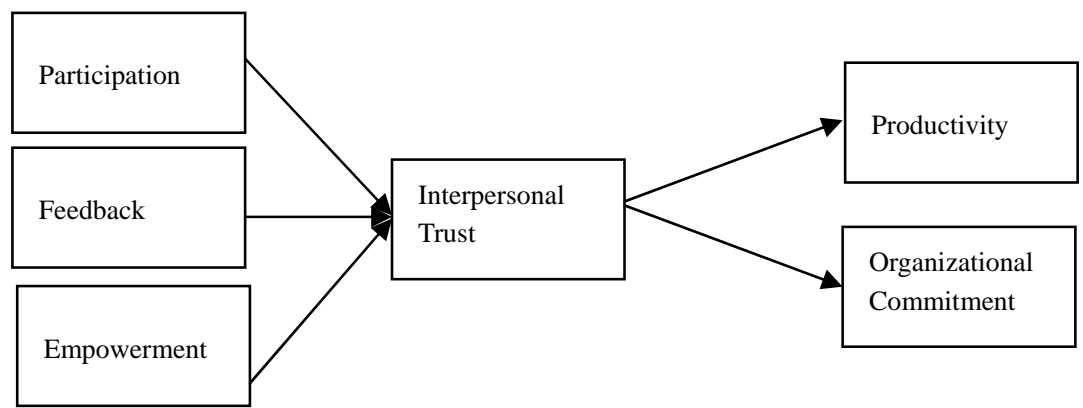

Figure 1. Conceptual Model of Trust by Nyhan-2000

\section{References}

Ashforth, B. E., Harrison, S. H., \& Corley, K. G. (2008). Identification in Organizations: An Examination of Four Fundamental Questions. Journal of Management, 34(3), 325-374. http://dx.doi.org/10.1177/0149206308316059

Atkinson, S., \& Butcher, D. (2003). Trust in Managerial Relationships. Journal of Managerial Psychology, 18(4), 282-304. http://dx.doi.org/10.1177/0149206308316059

Augistine, N. R. (1995). Managing the Crisis You Tried to Prevent. Harward Business Review, 73(6), 147-158. http://dx.doi.org/ 10.1016/S0267-3649(00)88914-1

Bambacas, M. (2008). Interpersonal communication skills that enhance organizational commitment. Journal of Communication Management, 12(1), 51-72. http://dx.doi.org/10.1108/18363261080001589

Bartram, T., \& Casimir, G. (2007). The relationship between leadership and follower in-role performance and satisfaction with the leader the mediating effects of empowerment and trust in the leader. Leadership \& Organization Development Journal, 28(1), 4-19. http://dx.doi.org/10.1108/01437730710718218

Bijlsma, K., \& Koopman, P. (2003). Introduction: trust within organizations. Free University Amsterdam, The Netherlands Personnel Review, 32(5), 543-555.

Blois, K. (1998). A trust interpretation of business to business relationships: a case-based discussion. Management Decision, 35(5), 302-308.

Brewer, A. M. (1996). Developing commitment between managers and employees. Journal of Managerial Psychology, 11(4), 24-34. http://dx.doi.org/10.1108/02683949610117599

Chiang, C. F., \& Jang, S. C. (2008). The Antecedents and Consequences of Psychological Empowerment: The Case of Taiwan's Hotel Companies. Journal of Hospitality \& Tourism Research, 32(1), 40-61. http://dx.doi.org/10.1177/1096348007309568

Coates, D. E. (1996). Multi-source feedback: seven recommendations. Career Development International, 1(3), 32-36.

Connell, J., \& Ferres, N. (2003). Engendering trust in manager-subordinate relationships Predictors and outcomes. Personnel Review, 32(5), 569-587. http://dx.doi.org/10.1108/00483480310488342

Costa, A. C. (2003). Work team trust and effectiveness. Personnel Review, 32(5), 605-622. http://dx.doi.org/10.1108/00483480310488360

Costigan, R. D., Insinga, R. C., Berman, J. J., Ilter, S. S., Kranas, G., \& Kureshov, V. A. (2006). A Cross-Cultural Study of Supervisory Trust. International Journal of Manpower, 27(8), 764-787. http://dx.doi.org/10.1108/01437720610713549

DeNisi, A., \& Kluger, A. (2000). Feedback effectiveness: can 360-degree appraisals be improved?. Academy of Management Executive, 14(1), 129-139. http://dx.doi.org/10.5465/AME.2000.2909845

Dietz, G. (2006). Measuring trust inside organizations. Personnel Review, 35(5), 557-588. http://dx.doi.org/10.1108/00483480610682299

Erdem, F., \& Zen, J. (2003). Cognitive and affective dimensions of trust in developing Team performance. Team Performance Management: An International Journal, 9(5/6), 131-135.

Ferrin, D. L., Bligh, M. C., \& Kohles, J. C. (2007). Can I Trust You to Trust Me? A Theory of Trust, Monitoring, and Cooperation in Interpersonal and Intergroup Relationships. Group and Organization Management, 
32(4), 465-499. http://dx.doi.org/10.1177/1059601106293960

Gilder, D. D. (2003). Commitment, trust and work behavior: The case of contingent workers. Personnel Review, 32(5), 588-604. http://dx.doi.org/10.1108/00483480310488351

Gillespie, N. A., \& Mann, L. (2004). Transformational leadership and shared values: the building blocks of trust. Journal of Managerial Psychology, 19(6), 588-607. http://dx.doi.org/10.1108/02683940410551507

Gordon, \& Scott, R. (2006). The role of interpersonal trust and vigilance in the process of entrepreneurial opportunity recognition using social networks. In Gillin, L. Murray (Ed.), Regional Frontiers of Entrepreneurship Research (pp. 42-61). Swinburne University of Technology, Melbourne, Unitec, Auckland.

Henkin, A. B., \& Moye, M. J. (2006). Exploring associations between employee empowerment and interpersonal trust in managers. Journal of Management Development, 25(2), 101-117. http://dx.doi.org/10.1108/02621710610645108

Klidas, Antonis, Peter T. van den Berg, \& Celeste, P. M. Wilderom. (2007). Managing employee empowerment in luxury hotels in Europe. International Journal of Service Industry Management, 18(1), 70-88. http://dx.doi.org/10.1108/09564230710732902

Knippen, J. T., \& Green, T. B. (1996). How to get feedback from your boss. Employee Counseling Today. The Journal of Workplace Learning, 8(5), 13-16. http://dx.doi.org/10.1108/13665629610127744

Ladd, B. S., Travaglione, A., \& Marshall, V. (2006). Causal inferences between participation in decision making, task attributes, work effort, rewards, job satisfaction and commitment. Leadership \& Organization Development Journal, 27(5), 399-414. http://dx.doi.org/10.1108/01437730610677990

Liu, X., Magjuka, R., \& Lee, S. (2008). An Examination of the Relationship among Structure, Trust, and Conflict Management Styles in Virtual Teams. Performance Improvement Quarter, 21(1), 77-93. http://dx.doi.org/10.1002/piq.20016

Luo, Y. (2002). Building Trust in Cross-Cultural Collaborations: Toward a Contingency Perspective. Journal of Management, 28(5), 669-694. http://dx.doi.org/10.1177/014920630202800506

McAllister, D. J. (1995). Affect- and cognition-based trust as foundations for interpersonal cooperation in organizations. Academy of Management Journal, 38(1), 24-59. http://dx.doi.org/10.2307/256727

Mishra, A. K. (1996). Organizational responses to crisis: the centrality of trust. In Kramer, A. M. \& Tyler, T. R. (Eds.), Trust in Organizations (pp. 262-87). Thousand Oaks, CA: Sage.

Nooteboom, B. (2003). Learning to Trust. Paper for Symposium La structure cognitive de la confiance, Ecole des Hautes Etudes en Sciences Sociales, Paris, 25-27 September.

Nyhan, R. C. (2000). Changing the Paradigm: Trust and its Role in Public Sector Organizations. American Review of Public Administration, 30(1), 87-109. http://dx.doi.org/10.1177/02750740022064560

Perry, R. W. (2004). The Relationship of Affective Organizational Commitment with Supervisory Trust. Review of Public Personnel Administration, 24(2), 133-149. http://dx.doi.org/10.1177/0734371X03262452

Pratt, M. G. (1998). To be or not to be? Central questions in organizational identification. In D. A. Whetten \& P. C. Godfrey (Eds.), Identity in organizations: Building theory through conversations (pp. 171-207). Thousand Oaks, CA: Sage.

Robbins, S. P., \& Coulter, M. (2005). Management (8th ed.). Printice-Hall.

Steelman, L. A., \& Rutkowski, K. A. (2004). Moderators of employee reactions to negative feedback. Journal of Managerial Psychology, 19(1), 6-18. http://dx.doi.org/10.1108/02683940410520637

Stinglhamberi, F., \& Vandenberghe, C. (2003). Organizations and supervisors as sources of support and targets of commitment: a longitudinal study. Journal of Organizational Behavior, 24, 251-270. http://dx.doi.org/10.1002/job.192

Tan, H. H., \& Tan, C. S. (2000). Toward the differentiation of trust in supervisor and trust in organization. Genetic social General Psychology Monographs, 126(2), 241-60.

Thoms, P., Dose, J. J., \& Scott, K. S. (2002). Relationships between Accountability, Job Satisfaction, and Trust. Human Resource Development Quarterly, 13(3), 307-323. http://dx.doi.org/10.1002/hrdq.1033

Tzafrir, S. S. (2004). The consequences of emerging HRM practices for employees' trust in their managers. 
Personnel Review, 33(6), 628-647. http://dx.doi.org/10.1108/00483480410561529

Wang, Y. (2003). Trust and decision-making styles in Chinese township-village enterprises. Journal of Managerial Psychology, 18(6), 541-556. http://dx.doi.org/10.1108/02683940310494377

Wech, B. A. (2002). Trust Context, Effect on Organizational Citizenship Behavior, Supervisory Fairness, and Job Satisfaction Beyond the Influence of Leader-Member Exchange. Business \& Society, 41(3), 353-360. http://dx.doi.org/10.1177/0007650302041003006

Young, L. (2006). Trust: looking forward and back. Journal of Business \& Industrial Marketing, 21(7), 439-445. http://dx.doi.org/10.1108/08858620610708920

Zhang, A. Y., Tsui, A. S., Song, L. J., Li, C., \& Jia, L. (2008). How do I trust thee? The employee-organization relationship, supervisory support, and middle manager trust in the organization. Human Resource Management, 47(1), 111-132. http://dx.doi.org/10.1002/hrm.20200 